\title{
Role of Tooth Sectioning in Reducing Inferior Alveolar Nerve Damage During Surgical Removal of Mandibular Impacted Third Original Molar Article
}

\author{
Mohammad Al-Sehimy, Ahmed Jan, Maisa Al-Sebaei \\ Oral and Maxillofacial Surgery Department, King Abdulaziz University, Saudi Arabia.
}

\begin{abstract}
A prospective study on 100 patients presented with a mesioangular impacted mandibular third molar in close proximity to the inferior alveolar nerve canal (IANC) was done to evaluate the efficacy of tooth sectioning in reducing the incidence of inferior alveolar nerve (IAN) injury during their surgical removal. The patients were divided into two groups : group A, where tooth sectioning was not performed, and group B, where tooth sectioning was performed. Patients were recalled 7 days, 15 days, 30 days , 3 months, and 6 months postoperatively for evaluation of nerve injury and its recovery. A total of 13 patients suffered from nerve damage out of which 10 patients belonged to group A (1050/ or 20\%) and 3 patients belonged to group B (350/ or $6 \%$ ). All patients showed complete recovery from nerve damage within 6 months except 1 patient . It was concluded from this study that tooth sectioning significantly reduces the incidence of nerve damage by $14 \%$. Deviation of the IANC, increased depth of the impacted tooth, intraoperative IO hemorrhage within socket, nerve exposure, and increased duration of procedure were found to be significant risk factors associated with nerve injury.
\end{abstract}

Key Words: Tooth sectioning, Impacted mandibular third molar, Inferior alveolar nerve canal (IANC) deficit, Neurosensory disturbances.

Received:29 November 2018, Accepted:13 December 2018

Corresponding Author: Mohammad Al-Sehimy, Oral and Maxillofacial Surgery Department, King Abdulaziz University, Saudi Arabia, Egypt, E-mail: 00966581009530, Tel.: mmelsehimy@hotmail.com

ISSN: 2090-097X, October 2018, Vol. 9, No. 4

\section{INTRODUCTION}

Injury to the inferior alveolar nerve (IAN) is amongst one of the most common complications associated with the removal of impacted mandibular third molars. It occurs primarily due to the proximity of root apices to the inferior alveolar nerve canal (IANC) ${ }^{[1]}$. The frequency of temporary IAN injury is 0.5 to $5 \%$, whereas permanent injury is less than $1 \%{ }^{[2]}$ and expressed as numbness in lower lip, chin, difficulty in phonation and mastication, drooling of fluids and saliva, and allodynia ${ }^{[3]}$. Sensory nerve damage can be classified as paresthesia, dysesthesia, and anesthesia which occur as a result of neuropraxia, axonotmesis, and neurotmesis respectively ${ }^{[4]}$.

Thus, to minimize the IAN damage following third molar surgery, several methods have been proposed like partial odontectomy ${ }^{[5]}$, orthodontic-assisted extraction ${ }^{[5]}$, and tooth sectioning technique ${ }^{[3]}$. Furthermore, tooth sectioning decreases the arc of rotation of a tooth, reduces the zone of retention by fragmentation, and preserves the bone and adjacent anatomical structures ${ }^{[3]}$.

Based on the hypothesis that tooth sectioning reduces the risk of nerve damage, we undertook a study with an aim to evaluate the role of the tooth sectioning technique in reducing IAN damage following surgical removal of an impacted mandibular third molar. The objective of the study was also to ascertain the correlation of age, gender, radiographic sign, depth, Pell and Gregory classification, duration of procedure, and intraoperative hemorrhage or exposure of nerve with the incidence of nerve damage.

\section{PATIENTS AND METHODS}

A prospective double-blind study (patient and examiner were blinded) was undertaken on patients who reported to the outpatient department of oral and maxillofacial surgery, faculty of dentistry, King Abdulaziz University. Patients were collected for the surgical removal of a mandibular third molar from 2012 to 2014. Clearance was obtained from the Institutional Ethics Committee, and informed written consent was signed by the patients before enrollment. Enrolled patients were radiographically assessed using intraoral periapical radiograph, panoramic radiograph and cone beam radiograph to determine the type of impaction and the radiographic sign of close proximity to the IANC as shown in (Table 1). Inclusion and exclusion criteria are listed in (Table 2). 
Table 1 : The relationship between the IANC and lower third molar roots ${ }^{[6,7]}$, Radiographic criteria:

\begin{tabular}{|c|c|c|}
\hline & IANC and lower third molar roots & Radiographic criteria \\
\hline 1 & Darkening of root & Impingement of canal on the tooth root results in loss of density of the root so the root appears darker ${ }^{[6]}$. \\
\hline 2 & Interruption of white line & $\begin{array}{l}\text { White line constitutes the "roof" and "floor" of the IANC. These lines appear on a radiograph due to the dense } \\
\text { structure of the canal walls. The white line considered to be interrupted if it disappears immediately before it } \\
\text { reaches the tooth structure; either one or both lines may be involved }{ }^{[6]} \text {. }\end{array}$ \\
\hline 3 & Deviation of canal & $\begin{array}{l}\text { The canal is considered to be diverted if, when it crosses the mandibular third molar, it changes direction (upward } \\
\text { displacement usually) }{ }^{[6]} \text {. }\end{array}$ \\
\hline 4 & Narrowing of the canal & $\begin{array}{l}\text { Narrowing or reduction of the diameter of the IANC when it crosses the root of the third molar occurs due to } \\
\text { the downward displacement of the upper border of the canal or the displacement of the upper and lower borders } \\
\text { toward each other with an hourglass appearance. The hourglass form indicates a partial encirclement of the canal } \\
\text { or a complete encirclement }{ }^{[6]} \text {. }\end{array}$ \\
\hline 5 & Narrowing of root & $\begin{array}{l}\text { Narrowing of the root where the canal crosses it implies that the greatest diameter of the root has been involved } \\
\text { by the canal or that there is deep grooving or perforation of the } \operatorname{root}^{\left[{ }^{6]}\right.} \text {. }\end{array}$ \\
\hline 6 & Deflection of root & $\begin{array}{l}\text { Deflected root or roots hooked around the canal are seen as an abrupt deviation of the root, when it reaches the } \\
\text { inferior alveolar canal }{ }^{[6]} \text {. }\end{array}$ \\
\hline 7 & Bifid root apex & $\begin{array}{l}\text { This sign appears when the inferior alveolar canal crosses the apex and is identified by the double periodontal } \\
\text { membrane shadow of the bifid apex }{ }^{[6]} \text {. }\end{array}$ \\
\hline 8 & Superimposition & Superimposition of the root(s) of the mandibular third molar and mandibular canal ${ }^{[7]}$. \\
\hline 9 & Contact & Root(s) of the mandibular third molar contact with the superior border of the mandibular canal ${ }^{[7]}$. \\
\hline
\end{tabular}

Table 2: Inclusion and exclusion criteria:

\begin{tabular}{lll}
\hline \multicolumn{1}{c}{ Inclusion criteria } & & \multicolumn{1}{c}{ Exclusion criteria } \\
\hline 1. & $\begin{array}{l}\text { Teeth with any radiographic signs of a direct relationship between the } \\
\text { nerve and mandibular canal as depicted in Table 1. }\end{array}$ & $\begin{array}{l}\text { An impacted mandibular third molar other than mesioangular, classes I } \\
\text { and II, Positions A, B, and C impaction. }\end{array}$ \\
2. A mesioangular impacted mandibular third molar. & 2. & Any systemic problems contraindicating surgery. \\
3. Classes I and II impaction. & 3. & Local or systemic neurological problems. \\
4. $\quad \begin{array}{l}\text { Positions A, B, and C classification, of a direct relationship to the nerve } \\
\text { and mandibular canal as depicted in Table 1. }\end{array}$ & Any psychological disturbances. \\
5. All the teeth with complete root formation. & \\
6. The presence of the second molar in occlusion. &
\end{tabular}

Included patients are randomly divided into two groups: group A involved subjects on whom tooth sectioning was not performed whereas group B included subjects on whom tooth sectioning was performed. Randomization was done by drawing paper from a box containing numbers from 1 to 100 ; odd numbers were assigned to group A and even numbers were placed in group B. All the patients were operated by the same surgeon. The patients were prepared and anesthetized using $2 \%$ lignocaine for IAN block. Access was achieved using distal and gingival incision lines. A lowrotation motor under abundant saline irrigation was used to remove the occlusal, buccal and distal bone around the teeth. In group B tooth was sectioned in two halves (midline splitting, horizontal/vertical) using suitable burs, while in group A, tooth was removed with only bone removal and without sectioning. The wound was closed with 30 - black silk suture. Postoperatively, an antibiotic (amoxicillin 500 $\mathrm{mg}$ thrice a day) and an analgesic (diclofenac $50 \mathrm{mg}$ twice a day) were then prescribed for 5 days.

Patients were recalled 7 days later for suture removal, and sensory nerve testing was then performed to evaluate IAN damage by an examiner (blinded). Primarily, subjective evaluation was done by asking the patient for any change in sensation of the lower lip and chin of the same side of operation. If any altered objective sensory tests like brush directional stroke using a painting brush ${ }^{[1]}$, two-point discrimination via a caliper ${ }^{[8]}$, light touch test using a cotton $\operatorname{swab}^{[1]}$, and pin prick test via a probe ${ }^{[8]}$ were then performed. The other unaffected side was used as a control. The pattern of sensory loss was measured based on paresthesia, dysesthesia, and anesthesia. Injured patients were then monitored after 15 days, 1 month, 3 months, and 6 months postoperatively. At every follow-up, the affected area was objectively tested and was considered to be recovered if the patient did not feel impairment of sensation and objective tests returned to normality. Sensory impairment if subsided within 6 months duration was considered temporary, and if it remained unresolved after 6 months, it was regarded as permanent ${ }^{[9]}$.

Data analysis was carried out with the Statistical Package for Social Sciences (SPSS) 15.0 for Windows. Chi square test of significance (X2) was carried out to establish an association of nerve injury with age, gender, depth of impacted tooth, radiographic sign, operative time, and method of surgery. The statistical significance was considered when $P<0.05$. 


\section{RESULTS}

The mean age of the patients included in the study was 28.23 years (Table 3). The male/female ratio was 11: 9 . Out of 100 patients, 51 patients $(51 \%)$ presented with an impacted mandibular third molar on the right side and 49 patients $(49 \%)$ on the left side. Pell and Gregory class I was discovered in $27(27 \%)$ patients and class II in 73 $(73 \%)$ patients. Pell and Gregory position A was seen in $23(23 \%)$, position B in $58(58 \%)$, and position C in 19 (19\%) patients. The most frequently observed radiographic sign indicating close proximity of the third molar root to the IANC was interruption of the white line seen in $27 \%$ (Table 4 ). Nerve injury was noticed in 13 patients $(13 \%)$ out of which temporary nerve deficit was observed in 12 patients and permanent nerve damage in 1 patient (Table 5).

Table 3: Age distribution

\begin{tabular}{ccc}
\hline Age group (years) & No. of patients & Percent \\
\hline 10-20 (second decade) & 10 & 10 \\
$21-30$ (third decade) & 57 & 57 \\
$31-40$ (fourth decade) & 27 & 27 \\
$41-50$ (fifth decade) & 05 & 5 \\
$51-60$ (sixth decade) & 01 & 1 \\
\hline
\end{tabular}

Table 4: Radiographic signs of close proximity of the third molar root to the IANC

\begin{tabular}{lc}
\hline \multicolumn{1}{c}{ Radiographic sign } & No. of patients \\
\hline Interruption of white line & 27 \\
Contact & 21 \\
Darkening + interruption of white line & 18 \\
Darkening & 12 \\
Superimposition & 9 \\
Root deviation & 5 \\
Narrowing of canal & 3 \\
Deviation of canal & 2 \\
Narrowing of root & 2 \\
Bifid apex & 1 \\
\hline
\end{tabular}

Table 5: Type of nerve injury

\begin{tabular}{|c|c|}
\hline Type of nerve injury & No. of patients \\
\hline Nerve injury absent & 87 \\
\hline Nerve injury present & 13 \\
\hline - $\quad$ Permanent & 1 \\
\hline - Temporary & 12 \\
\hline
\end{tabular}

Nerve injury was discovered in $20 \%$ of cases in the second decade, $10.6 \%$ of cases in the third decade, $11.1 \%$ of cases in the fourth decade, $20 \%$ of cases in the fifth decade, and $100 \%$ of cases in the sixth decade. Numerically, nerve injury was maximum in the sixth decade but it was not statistically significant (Table 6).

Table 6: Comparison between age and nerve injury

\begin{tabular}{ccccccc}
\hline Age (years) & No. of patients & No nerve damage & Nerve damage present & Nerve damage percent & $X^{2}$ & $P$ value \\
\hline $10-20$ & 10 & 8 & 21 & 6 & 20 & 7.74 \\
$21-30$ & 57 & 24 & 3 & 10.6 & \\
$31-40$ & 27 & 4 & 1 & 20 & \\
$41-50$ & 05 & 0 & 1 & 100 & \\
$51-60$ & 01 & & & & \\
\hline
\end{tabular}

Seven female patients (745/ or $15.6 \%$ ) and 6 male patients $(655 /$ or $11 \%)$ suffered from nerve damage, which was statistically insignificant (Table 7).

Nerve damage was observed in 3 patients of class I (327/ or $11.1 \%)$ and 10 patients of class II (1073/ or 13.7\%). Statistically, Pell and Gregory classification and nerve injury were found to be insignificant (Table 8).

IAN injury noticed in Pell and Gregory position A was $8.7 \%(223 /)$, in position B was $6.8 \%(458 /)$, and in position C was $36.9 \%(719 /)$. A statistically significant association was found between Pell and Gregory position and IAN injury suggestive of greater chances of nerve injury when the depth of an impacted third molar increases (Table 9).

The results were statistically significant, suggestive of deviation of the canal (22/ or $100 \%)$ being the most common radiographic sign associated with nerve injury, followed by interruption of white line along with the darkening of the root $(618 /$ or $33.3 \%)$ (Table 10$)$.

Intraoperative (IO) findings such as hemorrhage with or without nerve exposure were observed in 11 patients (11\%). Out of 11 patients, 9 patients $(81.81 \%)$ had nerve damage which was statistically significant, indicating that the presence of intraoperative hemorrhage with or without nerve exposure maximizes the chances of nerve damage (Table 11).

Duration of the procedure greatly influences the nerve damage. Time required in completing the procedure from incision to removal of the third molar out of the socket ranged from 10 to $42 \mathrm{~min}$. None of the patients suffered from neurosensory deficit when the procedure was completed within $20 \mathrm{~min}$, whereas procedures consuming more than 20 min displayed a higher incidence of nerve injury. Maximum damage to the nerve was observed for 
procedures taking more than $30 \mathrm{~min}$, which was statistically

significant (Table 12).

Table 7: Comparison between gender and nerve damage

\begin{tabular}{ccccccc}
\hline Gender & No. of patients & No nerve damage & Nerve damage & Nerve damage percent & $\mathrm{X}^{2}$ & $P$ value \\
Female & 45 & 38 & 7 & 15.6 & 0.47 & 0.49 \\
Male & 55 & 49 & 6 & 11 & Not significant \\
\hline
\end{tabular}

Table 8: Comparison between Pell and Gregory class and nerve damage

\begin{tabular}{ccccccc}
\hline Class & No. of patients & Nerve damage Absent & Nerve damage present & Nerve damage percent & $X^{2}$ & $P$ value \\
I & 27 & 24 & 3 & 11.1 & 0.12 & 0.73 \\
II & 73 & 63 & 10 & 13.7 & Not significant \\
\hline
\end{tabular}

Table 9: Comparison between Pell and Gregory position and nerve damage

\begin{tabular}{ccccccc}
\hline Gender & No. of patients & Nerve injury Absent & Nerve injury present & Nerve injury percent & $X^{2}$ & $P$ value \\
A & 23 & 21 & 54 & 2 & 8.7 & 11.84 \\
B & 58 & 12 & 7 & 6.8 & Significant \\
C & 19 & 76.9 & 360 & \\
\hline
\end{tabular}

Table 10: Comparison between radiographic signs and nerve damage

\begin{tabular}{|c|c|c|c|c|c|c|c|}
\hline Radiographic sign & No. of patients & Nerve injury Absent & Nerve injury present & Nerve injury percent & $\mathrm{X}^{2}$ & Pvalue & \\
\hline Bifid apex & 01 & 1 & 0 & 0 & 26.4 & 0.002 & Significant \\
\hline Contact & 21 & 21 & 0 & 0 & & & \\
\hline Darkening + interruption & 18 & 12 & 6 & 33.3 & & & \\
\hline Darkening of root & 12 & 11 & 1 & 8.3 & & & \\
\hline Deviation of canal & 02 & 0 & 2 & 100 & & & \\
\hline Deviation of root & 05 & 5 & 0 & 0 & & & \\
\hline Interruption & 27 & 23 & 4 & 14.9 & & & \\
\hline Narrowing of canal & 03 & 3 & 0 & 0 & & & \\
\hline Narrowing of root & 02 & 2 & 0 & 0 & & & \\
\hline Superimposition & 09 & 9 & 0 & 0 & & & \\
\hline
\end{tabular}

Table 11: Comparison between nerve injury and IO findings

\begin{tabular}{|c|c|c|c|c|c|c|c|}
\hline & No. of patients & Nerve damage Absent & Nerve damage present & Nerve damage percent & $\mathrm{X}^{2}$ & Pvalue & \\
\hline IO findings not present & 89 & 85 & 4 & 4.4 & 52.2 & 0.00 & Significant \\
\hline IO findings & 11 & 02 & 09 & 81.9 & & & \\
\hline 1) Hemorrhage & 06 & 01 & 05 & 83.3 & & & \\
\hline 2) Nerve exposure & 01 & 00 & 01 & 100 & & & \\
\hline 3) Both 1 and 2 & 04 & 01 & 03 & 75 & & & \\
\hline
\end{tabular}

Table 12: Comparison between time taken for completion of the procedure and nerve damage

\begin{tabular}{|c|c|c|c|c|c|c|}
\hline Time interval (min) & No. of patients & Nerve injury Absent & Nerve injury percent & $\mathrm{X}^{2}$ & Pvalue & \\
\hline$<10$ & 03 & 0 & 3 & 64.1 & $<0.0001$ & Significant \\
\hline $11-15$ & 13 & 0 & 13 & & & \\
\hline $16-20$ & 43 & 0 & 43 & & & \\
\hline $21-25$ & 21 & 2 & 19 & & & \\
\hline $26-30$ & 12 & 3 & 9 & & & \\
\hline$>30$ & 08 & 8 & 0 & & & \\
\hline
\end{tabular}


In group A (without sectioning), 10 patients (1050/ or $20 \%$ ) and in group B, 3 patients $(350 /$ or $6 \%$ ) suffered from nerve injury. The result was statistically significant, suggestive of greater damage to the IAN if the tooth was removed without sectioning (Table 13). The odds ratio was found to be 3.91, evocating that chances of IAN increases to almost four times if the tooth was removed without sectioning.
Out of 13 patients where neurosensory disturbance was noted, 6 patients $(46.2 \%)$ recovered within 1 month, 3 patients $(23 \%)$ within 3 months, and 3 patients $(23 \%)$ within 6 months, and only 1 patient (7.7\%) was recovery not observed within 6 months (Table 14). Thus, temporary nerve deficit was seen in 12 patients $(12 \%)$ and permanent in 1 patient $(1 \%)$ (Table 5).

Table 13: Comparison between method of surgery and nerve injury

\begin{tabular}{lcccccc}
\hline Method of surgery & No. of patients & Nerve injury Absent & Nerve injury present & Nerve injury percent & $X^{2}$ & $P$ value \\
Without sectioning & 50 & 40 & 47 & 10 & 20 & 4.3 \\
With Sectioning & 50 & 3 & 6.04 & Significant \\
\hline
\end{tabular}

Table 14: Recovery of nerve injuries

\begin{tabular}{lcc}
\hline Recovery period (months) & No. of patients & Percent \\
\hline $0-1$ & 6 & 46.3 \\
$1-3$ & 3 & 23 \\
$3-6$ & 3 & 23 \\
More than 6 & 1 & 7.3 \\
\hline
\end{tabular}

\section{DISCUSSION}

The removal of an impacted mandibular third molar appears to be the main etiology for IAN deficit owing to the close proximity of third molar roots to the IANC. Therefore, careful assessment and appropriate surgical technique are paramount to minimize the surgical morbidity. Amongst various options, tooth sectioning facilitates the removal of the tooth by decreasing the arc of rotation, reducing the zones of retention by fragmentation, and preserving sound bone and adjacent anatomical structures ${ }^{[3]}$.

The incidence of nerve injury found in this study was $13 \%$ which was higher than those of the reported studies conducted by Carmicheal and McGowan ${ }^{[1]}$ and Valmaseda et $a l^{[10]}$. The reason maybe because the procedure was being performed by a dull instruments and subsequent larger edema that might have led to a higher incidence of nerve injury in the study.

The highest incidence of nerve deficit was observed in the sixth decade and the minimum in the third decade, but the results were not statistically significant. This observation favors the study done by Valmaseda et al ${ }^{[10]}$, Gulicher et $a l^{[9]}$, Tay ${ }^{[8]}$, Blondeau ${ }^{[11]}$, Ahmed et $a l^{[12]}$, and Leung et $a l^{[13]}$, whereas Brann et $a l^{[14]}$ did not find any relationship of age to nerve injury. The reason for higher neurosensory disturbance in the older group has been attributed to increased bone density ${ }^{[1]}$, reduced bone elasticity ${ }^{[11,13]}$, root hypercementosis ${ }^{[11,13]}$, complete formation of the $\operatorname{root}^{[11]}$, reduced capacity for healing ${ }^{[11]}$, and reduced distance of the IANC from the buccal cortical margin and alveolar crest (normal distance of the buccal cortex is $4.9 \mathrm{~mm}$ and to the alveolar crest is $17.4 \mathrm{~mm})^{[15]}$. Tay et al concluded that an increase in age of 1 year raised the odds ratio of developing nerve damage by $6.9 \%{ }^{[8]}$.

Female patients (15.6\%) exhibited a higher incidence of nerve damage than male patients $(10.90 \%)$, although the results were statistically insignificant. Howe and Poyton $^{[16]}$ claimed that in females, the mandible is thin (i.e. less buccolingual thickness), because of which the distance between the tooth and the mandibular canal decreases, therefore causing more injury, whereas Valmaseda et $a l^{[10]}$ and Tay ${ }^{[8]}$ stated that females have lower risk of developing paresthesia following removal of impacted third molars.

The nerve damage noticed in Pell and Gregory class II was $13.7 \%$ which is higher than class I $(11.1 \%)$ but was statistically found to be insignificant. This observation was in accordance with Valmaseda et al ${ }^{[10]}$ who found that the ostectomy distal to the third molar was associated with a higher incidence of nerve damage.

A statistically significant relation of the depth of the impacted tooth to the incidence of nerve injury was found in the study (nerve positions $\mathrm{A}, \mathrm{B}$, and $\mathrm{C}$ was 8.7 , 6.8, and $36.9 \%$ respectively). The results are confluent with those found by Wofford et al ${ }^{[17]}$, Gulicher et al ${ }^{[9]}$, Valmaseda et $a l^{[10]}$, Ahmed et $a l^{[12]}$, and Leung et $a l^{[13]}$ as a deeper impacted tooth lie closer to the IANC, making it vulnerable to IAN damage. Reduced surgical accessibility and visibility could also contribute to the morbidity ${ }^{[13]}$.

In this study, a highly significant relation was established between deviation of the canal $(22 /$ or $100 \%)$ to nerve injury followed by darkening with interruption of the white line $(618 /$ or $33.3 \%)$, only interruption of the white line $(427 /$ or $14.9 \%)$, and only darkening $(112 /$ or $8.3 \%)$. No nerve damage was seen when signs like narrowing of the root, narrowing of the canal, deviation of the root, a bifid root apex, contact, and superimposition were present. These results of the study were similar to those found by Rood and Sheehab ${ }^{[6]}$, Valmaseda et $a l^{[10]}$, Koong et $a l^{[7]}$, Blaeser et $a l^{[18]}$, and Sedaghatfar et al. ${ }^{[19]}$, whereas Howe and Poyton ${ }^{[16]}$, Bell ${ }^{[20]}$, Gallesio et al ${ }^{[21]}$, and Leung et $a l^{[22]}$ observed that darkening of the root was the most common radiographic sign. Darkening of the root apex occurs because there is sudden decrease in the amount of tooth substance present between the apex and canal[23]. Interruption of the white line was considered as the most significant radiographic feature resulting in postsurgical 
nerve damage by various authors ${ }^{[6,19,20,24,25]}$. The white lines are lost when the borders of the canal are encroached upon by the tooth. Therefore, in cases of perforation, white lines would be lost. In cases where the apex is grooved by the canal only, the superior line is lost and the inferior line remains intact ${ }^{[23]}$. Narrowing of the canal may rarely cause neurosensory deficit because the formative dental papilla is soft and bone surrounding the canal is dense, so the tooth fails to compress the dense bone ${ }^{[23]}$. However, Gomes et $a l^{[26]}$, claimed that none of the panoramic radiographic signs were associated with an increased risks of IAN injury.

In 11 patients, intraoperative hemorrhage from the socket with or without nerve exposure was observed, of which 9 patients suffered from nerve damage (81.81\%), which is statistically significant, indicating that intraoperative hemorrhage/nerve exposure increases the incidence of nerve damage. The results correlate with the study done by Gulicher et a ${ }^{[9]}$, Tay ${ }^{[16]}$, Valmaseda et al ${ }^{[10]}$, Gallesio et $a l^{[21]}$, and Leung et al[22]. Pogrel ${ }^{[27]}$ stated that hemorrhage within the socket occurs because within the IANC, the inferior alveolar vein lies immediately superior to the IAN; thus, venous bleeding is encountered before the visualization of the nerve.

The incidence of nerve injury in the study increased when the time taken to complete the procedure (from placing the incision to removal of the tooth from the socket) was more than 20 min (maximum when $>30 \mathrm{~min}$ ). The result is consistent with that of Valmaseda et al ${ }^{[10]}$ who found that procedures longer than $20 \mathrm{~min}$ were associated with significant IAN injury because the duration of the procedure indirectly reflects the surgical difficulty.

Twenty percent of cases in group A (without tooth sectioning ) suffered from nerve injury, while in group $\mathrm{B}$ (with tooth sectioning), only $6 \%$ nerve injury was observed in the study. The result of the study was statistically significant, suggesting that greater damage to the IAN occurs without sectioning the tooth. The results are consistent with those of Valmaseda et a ${ }^{[10]}$ who stated that tooth sectioning reduces ostectomy resulting in lesser risk of IAN damage. The results are in variance to those of Bataineh et $a l^{[28]}$ and Genu et $a l^{[3]}$ who did not find any statistically significant association between nerve damage and tooth sectioning.

Most of the nerve injury recovered within the 6-month period was suggestive of being temporary in nature, and only $1 \%$ permanent nerve damage was observed. The results are in agreement with those of Wofford et al ${ }^{[17]}$, Miloro et $a l^{[29]}$, Carmicheal et $a l^{[1]}$, and Valmaseda et $a l^{[10]}$. A possible reason is that nerve injuries occurring after third molar extraction are mechanical in nature (compression, crush, laceration) and nerve regeneration after compression or less severe crush injuries resolve within 6 months. The IANC lodging the IAN prevents retraction or elastic recoil of the nerve if transected, and also the canal walls act as a conduit for sprouting axons, thus providing a favorable position for nerve healing and functional regeneration ${ }^{[30]}$.

\section{CONCLUSIONS}

1. In this study, there exists a $13 \%$ probability of encountering IAN damage when the radiographic sign of close proximity of the IANC to an impacted mandibular third molar is present.

2. Tooth sectioning significantly reduced the incidence of IAN damage by $14 \%$. Sectioning reduces the arc of rotation of the tooth and reduces the zones of retention by fragmentation while preserving sound bone and adjacent anatomical structures.

3. Nerve injuries encountered during surgical extraction of impacted third molars are usually temporary in nature resolving completely within 6 months' duration.

4. Deviation of the IANC, increased depth of the impacted tooth, IO hemorrhage within socket/ nerve exposure, and duration of the procedure exceeding 20 min were significant risk factors associated with nerve injury.

5. Old age, females, and ostectomy of distal bone to gain access to third molar were associated with nerve injuries, but their significance as risk factors could not be established in this study.

\section{RECOMMENDATION}

Surgical removal of impacted mandibular third molars should be performed in larger numbers of patients more than used in this study, in order to achieve better statistical analysis.

\section{REFERENCES}

1. Carmicheal FA, McGowan DA (1992) Incidence of nerve damage following third molar removal: a West of Scotland Oral Surgery Research Group study. Br J Oral Maxillofac Surg 30:78 - 82

2. Yadav S, Sachdeva A, Verma A (2011) Inferior alveolar nerve damage following removal of mandibular third molar teeth. Journal of Innovative Dentistry $1: 1-4$

3. Genu PR, Vasconcelos BCE (2008) Influence of tooth sectioning technique in alveolar nerve damage after surgery of impacted lower third molars. Int J Oral Maxillofac Surg 37:923 - 928

4. Libersa P, Savignat M, Tonnel A (2007) Neurosensory disturbances of the inferior alveolar nerve: a retrospective study of complaints in a 10-year period. J Oral Maxillofac Surg 65:1486 1489

5. Landi L, Manicone PF, Piccinelli S, Raia R (2010) Staged removal of horizontal impacted third molars to reduce risk of inferior alveolar nerve injury. J Oral Maxillofac Surg 68:442 - 446 
6. Rood JP, Shehab BAAN (1990) The radiological prediction of inferior alveolar nerve injury during third molar surgery. Br J Oral Maxillofac Surg $28: 20-25$

7. Koong B, Pharoah MJ, Bulsara M, Tennant M (2006) Methods of determining the relationship of the mandibular canal and third molars: a survey of Australian oral and maxillofacial surgeons. Aust Dent J 51(1):64 - 68

8. Tay ABG, Go WS (2004) Effect of exposed inferior alveolar neurovascular bundle during surgical removal of impacted lower third molars. J Oral Maxillofac Surg 62:592 - 600

9. Gulicher G (2001) Sensory impairment of the lingual and inferior alveolar nerves following removal of impacted mandibular third molars. Int J Oral Maxillofac Surg 30(4):306 - 12

10. Valmaseda-Castellón E, Berini-Aytés L, GayEscoda C (2001) Inferior alveolar nerve damage after lower third molar surgical extraction: a prospective study of 1117 surgical extractions. Oral Surg Oral Med Oral Pathol Oral Radiol Endod 92:377 - 83

11. Blondeau F, Daniel NG (2007) Extraction of impacted mandibular third molars: postoperative complications and their risk factors. JCDA 73(4):325 e

12. Ahmed A, Mohamed F, Hattab K (2009) Surgical extraction of impacted mandibular third molars: postoperative complications and their risk factors. Jamahiriya medical Journal 9(4):272 - 275

13. Leung YY, Cheung LK (2011) Risk factors of neurosensory deficits in lower third molar surgery: a literature review of prospective studies. Int J Oral Maxillofac Surg 40:1 - 10

14. Brann CR, Brickley MR, Shepherd JP (1999) Factors influencing nerve damage during lower third molar surgery. Br Dent J 186:514 - 516

15. Levine MH, Goddard AL, Dodson TB (2007) Inferior alveolar nerve canal position: a clinical and radiographic study. J Oral Maxillofac Surg 65:470 - 474

16. Sandstedt P, Sorenser S (1995) Neurosensory disturbances of trigeminal nerve. J Oral Maxillofac Surg 53:498-505

17. Wofford DT, Miller RI (1987) Prospective study of dysesthesia following odontectomy of impacted mandibular third molars. J Oral Maxillofac Surg $45: 15-19$

18. Blaeser BF, August MA, Donoff RB, Kaban LB, Dodson TB (2003) Panoramic radiographic risk factors for inferior alveolar nerve injury after third molar extraction. J Oral Maxillofac Surg 61:417-21
19. Sedaghatfar M, August MA, Dodson TB (2005) Panoramic radiographic findings as predictors of inferior alveolar nerve exposure following third molar extraction. J Oral Maxillofac Surg 63:3-7

20. Bell GW (2004) Use of dental panoramic tornographs to predict the relation between mandibular third molar teeth and inferior alveolar nerve. Radiological and surgical findings, and clinical outcome. $\mathrm{Br} \mathrm{J}$ Oral Maxillofac Surg 42:21 - 27

21. Gallesio C, Mattia B, Emanuele R, Paolo B (2010) Surgical extraction of impacted inferior third molars at risk for inferior alveolar nerve injury. Journal of Craniofacial Surgery 21(6):2003 - 2007

22. Leung YY, Cheung LK (2011) Correlation of radiographic signs, inferior dental nerve exposure, and deficit in third molar surgery. J Maxillofac Surg 69:1873 - 1879

23. Drage N, Renton T (2002) Inferior alveolar nerve injury related to mandibular third molar surgery: an unusual case presentation. Oral Surg Oral Med Oral Pathol Oral Radiol Endod 93:358 - 61

24. Nakagawa Y, Ishii H, Nomura Y, Watanabe NY, Hoshiba D, Kobayashi K et al (2007) Third molar position: reliability of panoramic radiography. $\mathrm{J}$ Oral Maxillofac Surg 65:1303-8

25. Tantanapornkul W, Okochi K, Fujiwara Y, Yamashiro M, Maruoka Y, Ohbayashi N et al (2007) A comparative study of cone beam computed tornography and conventional panoramic radiography in assessing the topographic relationship between the mandibular canal and impacted third molars. Oral Surg Oral Med Oral Pathol Oral Radiol Endod 103:253 - 259

26. Gomes AC, Vasconcelos BC, Silva ED, Caldas Ade F Jr, Pita Neto IC (2008) Sensitivity and specificity of pantomography to predict inferior alveolar nerve damage during extraction of impacted lower third molars. J Oral Maxillofac Surg 66:256 - 9

27. Pogrel A, Dorfman D, Fallah H (2009) The anatomic structure of the inferior alveolar neurovascular bundle in the third molar region. J Oral Maxillofac Surg 67:2452 - 54

28. Bataineh AB (2001) Sensory nerve impairment following mandibular third molar surgery. J Oral Maxillofac Surg 59:1012 - 1017

29. Miloro M, DaBell J (2005) Radiographic proximity of the mandibular third molar to the inferior alveolar canal. Oral Surg Oral Med Oral Pathol Oral Radiol Endod 100(5):545 - 9

30. Hillerup S (2008) Introgenic injury to inferior alveolar nerve: etiology, signs and symptoms, and observation on recovery. Int J Oral Maxillofac Surg 37:704 - 709 